\title{
Correction to: Consumption Ethics: A Review and Analysis of Future Directions for Interdisciplinary Research
}

\author{
Michal Carrington ${ }^{1} \cdot$ Andreas Chatzidakis $^{2} \cdot$ Helen Goworek $^{3} \cdot$ Deirdre Shaw $^{4}$
}

Published online: 13 March 2020

c) Springer Nature B.V. 2020

Correction to: Journal of Business Ethics

https://doi.org/10.1007/s10551-020-04425-4

In the published article the Acknowledgment section is missing. The following text should have been included:

Acknowledgement The authors were supported by ESRC Seminar Series funding under award ES/M002446/1 in a series entitled 'Ethics in Consumption: Interdisciplinary Perspectives'.
Publisher's Note Springer Nature remains neutral with regard to jurisdictional claims in published maps and institutional affiliations.

The original article can be found online at https://doi.org/10.1007/ s10551-020-04425-4.

Michal Carrington

Michal.Carrington@unimelb.edu.au

Andreas Chatzidakis

Andreas.Chatzidakis@rhul.ac.uk

Helen Goworek

Helen.Goworek@durham.ac.uk

Deirdre Shaw

Deirdre.Shaw@glasgow.ac.uk

1 University of Melbourne, Parkville, Australia

2 Royal Holloway University of London, Egham, UK

3 University of Durham, Durham, UK

4 University of Glasgow, Glasgow, UK 